\title{
Up above as a Complex Preposition
}

\author{
Hideo Hirao ${ }^{1}$ \\ ${ }^{1}$ Department of English Communication, Otemon University, Japan \\ Correspondence: Hideo Hirao, 2-1-15 Nishiai, Ibaraki City, Osaka, 567-8502, Japan. Tel: 81-72-641-9620. E-mail: \\ h-hirao@res.otemon.ac.jp \\ Received: December 25, 2013 \\ Accepted: January 10, 2014 \\ Online Published: January 20, 2014 \\ doi:10.5430/elr.v3n1p12 \\ URL: http://dx.doi.org/10.5430/elr.v3n1p12
}

\begin{abstract}
Hirao (2013) indicated that a string, up above, might be considered as a complex preposition. Using British National Corpus (BNC) as our main source of data, this article examines this string from the following three view points: 1. Distribution pattern as a complex preposition. 2. Zero derivation as a prepositional adverb. 3. Modification by adverbs. It is hoped that through these examinations, the string's status as a complex preposition in present-day English will be established.
\end{abstract}

Keywords: Complex preposition, Zero derivation, Prepositional adverb

\section{Introduction}

In his argument of three complex prepositions, up and above, down and below, and from bottom to top and across, Hirao (2013) indicated that two strings without and, up above and down below, might also be considered as complex prepositions. This article takes up the string up above and examines its status as a complex preposition from the following three view points. First, its distribution as a preposition will be examined. Second, we will see whether the string in question have zero derivation as a prepositional adverb. Finally, we will examine whether the string headed by up above can be modified by a number of adverbs. Use of the string up above in these three circumstances can be seen as conditions for its status as a complex preposition. If the string up above fulfills all these three conditions, we can safely grant the string as a complex preposition.

\section{Background}

Arguments on complex prepositions have not been very active. Quirk \& Mulholland (1964) argued for the existence of complex prepositions of the structure preposition plus noun plus preposition, i.e. in front of. To this argument, Seppänen, Bowen, \& Traugott (1994) denied the existence of complex prepositions of this type and insisted that they are instances of free forms. Hoffmann (2005), based on a large corpus study, demonstrated that they are real prepositions. Hirao (2013) indicated that there are even other type of complex prepositions which contain a lexical item and. In it he also pointed out that two strings, up above and down below, may be considered as complex prepositions.

\section{Research Design}

We will take up the string up above and examine its behavior as a complex preposition. As has been stated in the introduction, points to be examined are the following three syntactic considerations:

1. Distribution pattern as a complex preposition.

2. Zero derivation as a prepositional adverb.

3. Modification by adverbs.

If the string up above exhibits the same syntactic behavior in all these three points as single word prepositions, we may well regard the string as a complex preposition.

\section{Distribution Pattern}

A prepositional phrase headed by a preposition can be used in a number of syntactic functions. Leech \& Svartvik (2002, pp. 367-8) summarizes the main functions of prepositional phrases as in the following:

Adverbial

(1) We may need you to do some work in the evening. 
(2) To my surprise, the doctor phoned the next morning.

Modifier in a Noun Phrase

(3) Chelsea felt she had no chance of promotion.

(4) We've rented this cottage in the country for peace and quiet.

Verb Complement

(5) You don't seem particularly worried about the situation.

Adjective Complement

(6) I'm terribly bad at dates.

In the following, we will take up these various functions that a prepositional phrase may take and see whether the string headed by up above can be used in the same functions. In finding examples of these functions, we used British National Corpus (BNC) as our source of data. The section and line number of the examples listed will be stipulated after each example.

\subsection{Adverbial}

A prepositional phrase can be used as a sentence adverbial. Here are two examples from BNC:

(7) It was good to be a flyer, up above it all, godlike in your vision.

(BNC G0L 707)

(8) My lad took me blackberryin' a month or two back, up above the quarry, and I seen'em.'

\section{(BNC HTH 634)}

The string can be used as a place adverbial:

(9) And now fly up above the forest, and take on a human form.

(BNC CA5 178)

(10) She would tear into her staff you see and get it and then er an along the corridors you know, there's ledges up above the doors as they slide into each compartment.

(BNC K6M 664)

The string headed by up above may have a metaphorical meaning:

(11) I think the bit that stands up above the horizon is fine, I mean I think that gives you a good idea of what it would have been like had you been able to get the whole, or not perhaps the whole of it, but a lot more of the post up above the horizon simply by getting down lower.

(BNC HM2 339)

\section{2. Modifier in a Noun Phrase}

In the following examples, the phrase headed by up above act as a modifier of the head noun:

(12) But this idea of God as an object up above the world (or up above the universe) is firmly ruled out by all that these religions have to say about the divine nature.

(BNC AMT 1165)

(13) This talked about tormentosas, con gran aparato eléctrico, and we experienced one of these during an evening stroll up above the town and got completely drenched.

(BNC BNV 357)

(14) Tell her Jamie found four more sheep in the drifts up above the pass and they're alive.

(BNC H8X 251)

(15) Instead, some crumbled, some caused fear and crime and many led to isolation hundreds of feet up above the rest of the town, But back in 1952 something needed to be done to take us out of Victorian and Edwardian accommodation and into the second half of the 20th century.

(BNC K4V 2147)

The next example clearly shows that the string up above has a property of a preposition: 
(16) This name has survived as Thriddle but nowadays is taken to mean that area around and up above the old dressing mill at Red Dell Foot.

(BNC H0B 306)

In this example, up above is conjoined with another single word preposition, around. This strongly indicates that the string up above has the same syntactic function as around. Therefore the string up above should be considered to be a preposition in a complex form.

\subsection{Adjective Complement}

(17) This was high up above the Bay, on top of the hill.

(BNC ASN 2007)

(18) There, she was high up above the woods, but instead of being able to see all that was going on below for miles around, as she had expected, all she could see was - leaves!

\section{(BNC B0B 1368)}

In these examples, whether the constituent high is the head of an adjectival phrase or the adverbial modifying the following constituents may be a delicate question to answer. We will return to this question later.

\subsection{Intransitive Verb Complement}

The following two sections deal with verb complements. The first deals with intransitive verb complements, the second, transitive verb complements. Complements are so called because they are indispensable parts in verb phrases. In reality the decision as to whether a given prepositional phrase is a complement or an adverbial may be delicate. Most plausible examples are:

(19) In the river-bed, islands of rock stuck up above the imaginary water level.

(BNC AT3 1122)

(20) When Lord Hanson made his cash bid for Ranks Hovis McDougall a month ago the shares shot up above the $220 \mathrm{p}$ offer.

(BNC K97 6618)

(21) To his right the hill rose up above where he stood, then fell again to meet the next turn of the river.

(BNC FRF 200)

There is a unique construction in this category which involves the verb be:

(22) This can be clearly seen at St Oswald's in Gloucester, where the many phases of development are more clear in elevation than plan, and where, ironically, the earliest masonry is up above arches put in at a later date.

(BNC H8U 594)

The next example involves inversion:

(23) Up above Loch Morar is the craggy hill top by the name of Sgurr Bhuide.

(BNC A15 1320)

In these examples the string headed by up above constitutes a predicate adverbial and this construction is quite common among single word prepositions. For instance, we can easily find sentences which have the same construction as below:

$\mathrm{X}$ is $\{$ in, on, at, for, from, over, under, etc. $\}$ NP.

The ball is in a box.

The hotel is on the beach.

Mike is at the party.

This is for you.

The fact that the string up above can be used in a construction in which single word prepositions are commonly used indicates that the string has a property quite similar to that of single word prepositions.

4.5 Transitive Verb Complement

Here again as in the previous section, distinction between complement and adverbial may be in reality delicate. Here 
are the most plausible examples of transitive verb complements:

(24) When the man lifts his clothes up above the knee, he wishes then to place the head of the hanging object into the familiar hole which it, when of equal length, has often filled before.

(BNC BP4 148)

(25) Stretch your hands up above your head and as you stretch up, turn to face one leg.

(BNC C9Y 666)

(26) he auctioneer stuck his head up above the pulpit and the Campbell took a shot at it.

(BNC HWN 2114)

We find another example (cf. 16) in which the string up above is conjoined with a single word preposition:

(27) The bird symbolising the yearning for freedom man has, his desire to pull himself up above and beyond the limits and discomforts of his own restricted world.

(BNC HD8 191)

In this example, up above is conjoined with beyond. As with 16, this presents strong evidence that the string up above is functioning as a complex preposition.

\subsection{Discussion}

This section has shown that the string up above can be used in most of functions that single word prepositions may be used. Seen from distribution pattern, there is almost no difference between the string and single word prepositions.

\section{Prepositional Adverb}

Many of single word prepositions can be used as adverbs without morphological change. This zero derivation is a major extensional use of prepositions:

(28) They stayed in.

(29) A car went past.

The string up above can also be used as a prepositional adverb. It may be used as a post nominal modifier(30-32), a sentence adverb(33-35) or a predicate adverb(36):

(30) The way she felt about him seemed to sweep round her like the clouds up above.

(BNC HGD 3384)

(31) She hears a cough from one of the sleepers up above.

(BNC HGN 3673)

(32) Maggie's stomach seemed to stay behind somewhere up above and her hands gripped the edge of the seat anxiously.

(BNC HGK 789)

(33) Up above, two flying walkways in oak and steel traverse the space at third and fourth levels. (BNC APX 1082)

(34) Up above, the roof was wreathed in shadow, but Benny sensed the presence of something huge, lurking in the darkness.

(BNC FSR 663)

(35) Up above, the other man was clambering over the iron rail of the terrace, a dark and uncertain shape against the night sky.

(BNC G03 2487)

(36) There were rocks far below, and up above were broad shafts of light from great holes near the roof.

(BNC HA3 3618)

Thus the string up above can actually be used as a prepositional adverb. This fact supports that the string is originally a complex preposition and at the same time strongly indicates that the entire string in question is forming a unit of its own. 


\section{Adverb Modification}

Some adverbs are known to modify prepositional phrases that they precede:

(37) He was sitting right at the edge of the big brown chair.

(BNC ALH 223)

(38) Sand dunes are often the highest elevation not just on the coast but for miles inland.

(BNC ABG 926)

(39) But the process goes way beyond the top managers.

(BNC ABU 193)

If we could find these and other adverbs modifying the string headed by up above, we could say that the string is functioning as the head of a prepositional phrase in the same way that at, on and beyond are heads of prepositional phrases in above examples. In the following we will take up different adverbs one by one.

6.1 Right

Right is a commonly used adverb for prepositional phrases and it can also modify the string headed by up above:

(40) The erm much, given much more dominance in the picture by making it stand right up above the horizon.

(BNC HM2 380)

(41) or whatever you call it, right up above Clapham station, there's a light on top, miles from anywhere

(BNC KCS 1817)

\subsection{Just}

BNC contains one example of just modifying the string headed by up above:

(42) There's one at the back of the free, double one at the back of the freezer, so he's put it right this side so it's just up above it there.

(BNC KCW 1959)

6.3 Way

Way is modifying the string headed by up above in the following examples:

(43) Really? just a, you know, way up above the the main er thing, yeah.

(BNC KP5 3147)

(44) Way up above in the light at the top of the well Mrs Parvis was speaking but Dot knew it was nothing to do with her.

\section{(BNC AC5 1934)}

In 44, up above is a prepositional adverb. There is not any constituent after up above which may be directly dominated by the string, so it must be the only string that is being modified by way. Thus this example shows quite strongly that up above is functioning as a single grammatical unit.

6.4 High

In 4.3, we have cited examples in which high might be a head of an adjectival phrase taking an up above prepositional phrase as its complement. BNC contains one more example containing high up above where the main verb is not a linking verb:

(45) He felt detached, as if he was floating high up above them and the executioners were only playing with the useless bundle of flesh that had once been his body.

(BNC H9C 468)

Is this the sentence about floating high or floating up above them? In other words, what is the main constituent after the main verb? Returning to 17 and converting the sentence with an interrogative adverb where will shed some light into the question.

(17) This was high up above the Bay, on top of the hill.

Where was this?

?*It was high.

It was up above the Bay.

It was high up above the Bay. 
Looking at different answers to the question, it is likely that It is high is not an appropriate answer to the question. Thus, it might be fair to say that high in this case is modifying the constituents after it not the other way around.

\subsection{Another adverb}

We find another example of adverb modifying the string headed up above in BNC:

(46) These stéles discoïdales are formed of a roughly engraved stone disc on top of a sturdy, tapering base and you find them either buried well into the earth so that little shows above the ground except the disc or else standing clearly up above it (see Plate I).

(BNC FA2 326)

In this example, the adverb clearly does not express the manner in which the action, standing, is being performed, but it explains how the object in question is popping up on the surface of the earth. Thus the object of modification is the string headed by up above.

\subsection{Discussion}

This section examined existence of adverbs that modify the string headed by up above. Corpus data show that there exist a number of such adverbs. These examples clearly show that up above is functioning as a single grammatical unit in the same way as single ward prepositions in prepositional phrases.

\section{Conclusion}

We have examined syntactic behavior of the string up above and the entire phrase containing it and confirmed that the string exhibits almost the same distribution pattern as single word prepositions, that in the same way that many of single word prepositions can be used as prepositional adverbs, this string can be used alone as an independent adverbial (prepositional adverb), and that the phrase headed by up above, in parallel with prepositional phrases headed by single word prepositions, can be modified by a number of adverbs. These facts clearly demonstrates that the string up above is functioning as a complex preposition in present-day English. The remaining question at hand is the existence of a mirror image of up above on the opposite side, i.e. down below:

(47) The band was down below and then a loft, a long wooden just like a dance hall up above and they just did that and they just they had tables set and then they removed them for the dances.

\section{(BNC K6R 493)}

In this example both down below and up above are acting as prepositional adverbs. We will need to examine different aspects in usage of the string down below and establish its status as a complex proposition.

\section{References}

Crystal, D. (1980) A First Dictionary of Linguistics and Phonetics, London: Andre Deutsch.

Hirao, H. (2013) Three Complex Prepositions with And. International Journal of English Linguistics, 3, 2, 25-31. http://dx.doi.org/10.5539/ijel.v3n2p25

Hoffmann, S. (2005) Grammaticalization and English Complex Prepositions: A Corpus-based Study, Oxon: Routledge.

Hopper, P. J. \& Traugott, E. C. (1993) Grammaticalization, Cambridge: Cambridge University Press.

Hopper, P. J. \& Traugott, E. C. (2003) Grammaticalization ( $2^{\text {nd }}$ edn), Cambridge: Cambridge University Press. http://dx.doi.org/10.1017/CBO9781139165525

Inoue, A. (2012). 'Newly observed phraseological units functioning as group prepositions in contemporary English: the case of be on against and in and of itself.' A presentation read at the $5^{\text {th }}$ meeting of Japan Society for Phaseology held at Umeda Campus, Kwanseigakuin University, Japan on March 3, 2012.

Leech, G. \& Svartvik, J. (1975) A Communicative Grammar of English, London: Longman.

Leech, G. \& Svartvik, J. (1996) A Communicative Grammar of English $\left(2^{\text {nd }}\right.$ edn), London: Longman.

Leech, G. \& Svartvik, J. (2003) A Communicative Grammar of English ( $3^{\text {rd }}$ edn), London: Pearson.

Quirk, R. et. al. (1972) A Grammar of Contemporary English, London: Longman.

Quirk, R. et. al. (1985) A Comprehensive Grammar of the English Language, London: Longman.

Quirk, R. \& Greenbaum, S. (1973) A University Grammar of English, London: Longman.

Quirk, R. \& Mulholland, J. (1964) 'Complex prepositions and related sequences', English Studies (Supplement; Frstschrift for R. W. Zandvoort), 45: 64-73. http://dx.doi.org/10.1080/00138386408597188

Seppänen, A., Bowen, R. \& Traugott, E. C. (1994) 'On the So-called Complex Prepositions.' Studia Anglica Posnaniensia, 29, 3-29. 